\title{
Los lineamentta de Alberti y las artes liberales. Una relación entre la retórica y el gusto en De re aedificatoria
}

\author{
The lineamentta of Alberti and the liberal arts. \\ A relationship between rethoric and the taste in \\ "De re aedificatoria"
}

\author{
RAFAEl GARCía SÁNCHEZ \\ Dr. Arquitecto. Profesor Asociado \\ Escuela Técnica Superior de Arquitectura y Edificación. Universidad Politécnica de Cartagena (España) \\ rafael@sgbarquitectos.es
}

Recibido: $14 / 07 / 2015$

Aceptado: 26/09/2015

\section{Resumen}

Leon Battista Alberti fue un hombre de letras que también cultivó las artes serviles. Su labor arquitectónica es correlativa de su tratado, De re aedificatoria, donde establece las bases del ascenso de la arquitectura al ámbito de las artes liberales. Inaugura con Brunelleschi, entre otros, la modernidad en las artes visuales. Esta modernidad enlaza con la primacía de lo visual sobre lo oral, y permitirá a la pintura elevarse sobre las artes mecánicas. Para ello, introduce los lineamentta y la concinnitas como elementos retóricos y al cabo, como mecanismos que posibilitan la corrección, la interpretación, la reflexión y el conocimiento que tendrán su desenlace definitivo en la noción de gusto, tal y como sucede en las artes liberales.

Palabras clave

Renacimiento, humanidades, lineamentta, concinnitas, retórica, gusto. 


\begin{abstract}
Leon Battista Alberti was a man of letters who also cultivated the servile arts. His architectural work is correlative of his treatise, De re aedificatoria, where lays the foundation for the promotion of architecture to the field of the liberal arts. It opens with Brunelleschi, among others, modernism in the Visual Arts. This currency link to the primacy of the visual on the oral, and will allow paint to soar on the mechanical arts. To do this, enter the lineamentta the concinnitas as rhetorical elements and, as mechanisms enabling the correction, interpretation, reflection and knowledge that will have its final on the notion of taste denouement, as it happens in the liberal arts.
\end{abstract}

\title{
Keywords
}

Renaissance, humanities, lineamentta, concinnitas, rhetoric, taste.

Referencia normalizada: GARCÍA SÁNCHEZ, RAFAEL (2015): “Los lineamentta de Alberti y las artes liberales. Una relación entre la retórica y el gusto en De re aedificatoria". Arte y Ciudad. Revista de Investigación, no 8 (octubre), págs. 7-28. Madrid. Grupo de Investigación Arte, Arquitectura y Comunicación en la Ciudad Contemporánea, Universidad Complutense de Madrid.

Sumario: 1.- El fin de lo medieval: de lo lógico a lo poético. 2.- Vitruvio interpretado por Alberti. 3.- El trívium invertido: el primado de la retórica. 4.- Concinnitas: Cicerón en arquitectura. 5.- Los lineamentta como principio retórico: de lo servil a lo liberal. 6.- $\mathrm{Li}$ neamentta y buen gusto: saber mirar y saber "a-probar". 7.- Conclusión. 8.- Bibliografía.

Fuentes: Para los textos de Alberti, hemos seguido el libro de Joaquín Arnau, La teoría de la arquitectura en los tratados: Alberti, que se basa en la edición de Il Polofilo en sus dos textos, el latino original y la traducción italiana moderna, sin perder de vista la única traducción castellana, atribuida a Francisco Lozano (Arnau, 1988: 27). Y para los de Vitruvio el libro del mismo autor, La teoría de la arquitectura en los tratados: Vitruvio, que sigue la edición bilingüe de Choisy traducida por el autor (Arnau, 1987: 24). 
¿Por qué te gusta obrar así?

Simplemente me gusta

(Aristóteles, 8: 1206 a37-1206 b4)

\section{El fin de lo medieval: de lo lógico a lo poético.}

Como es sabido, el descubrimiento de las obras aristotélicas y su integración en los programas de enseñanza bajomedievales, incrementaron la importancia de la ciencia, la lógica y la técnica. Platón fue sensiblemente orillado por Aristóteles y su lógica se introdujo en la gramática, la filosofía y la teología medieval, quedando reducidas la retórica y la poética a meros conocimientos técnicos regulados por recetas y normas. La poética se convirtió en mera técnica, degradada a pericias accidentales y superfluas de índole retórica. La libre y singular lectura de los clásicos fue reemplazada por el estudio de reglas, originando una crisis del clasicismo en el siglo XIII como ha puesto de relieve el gran experto en el pensamiento medieval Etienne Gilson (1958: 44), en su obra La filosofía en la Edad Media:

En todas las escuelas de Occidente se produce una verdadera insurrección de la lógica contra las seis restantes artes liberales; insurrección a la que se sigue muy pronto la invasión de las facultades de artes por la filosofía de Aristóteles.

Desde entonces, en la teoría y en la práctica, se produjo una excitación de lo racional. Los artistas bajomedievales no consideraban la actividad artística como actividad creativa o autoexpresiva:

En la visión medieval no existía, por así decirlo, una problemática de la creación artística, porque esta visión en el fondo negaba tanto al sujeto como al objeto (ya que el arte no era para ella más que la materialización de una forma, que ni dependía de la manifestación de un objeto real ni era producida por la actividad de un sujeto real, sino más bien correspondía a una imagen preexistente en el alma del artista) (Panofsky, 2013: 65).

La división de las artes se complicó dado que ni la invención ni la autoexpresión obtuvieron un lugar apropiado, ignorándose la dimensión específica del conocimiento que se llevaba a cabo en la poesía. La poesía quedó reducida a un tipo de destreza consistente en hacer deleitables conocimientos ya adquiridos, pero en ningún caso servía para revelar conocimientos nuevos. Poético era el adorno extrínseco y accidental al objeto que no hacía visible su sustancia, solo decoraba agradablemente. 
Para Tomás de Aquino la poesía era considerada doctrina ínfima: “Procedere per similitudines varias et repraesentationes, est proprium poeticae, quae est infima inter omnias doctrinas" ${ }^{\prime 1} \mathrm{Y}$ en su visión racional de los fenómenos sentencia que las cosas poéticas no son percibidas por la razón humana a causa de la escasa verdad que encierran: "Poetica non capiuntur a ratione humana propter defectum veritatis qui est in eis" (Tomás de Aquino, 1965: $101,2$ ad 2) $)^{2}$.

Dante, en plena ebullición aristotélica, inicia la defensa del arte literario elevando la poesía a la más alta cota de expresión humana. Sin ser un autor renacentista, desde él puede atisbarse el horizonte del humanismo ${ }^{3}$. Será a partir de él cuando empiece a tenerse la poesía, no sólo como aceptación de lo místico, sino como su más cabal expresión.

Vasari da buena cuenta de la importancia de las letras en el ámbito de las artes visuales cuando sobre la vida de Leon Battista Alberti afirma que:

1 "Hablar mediante comparaciones e imágenes es propio de la poesía, que es la más baja de todas las ciencias" (Tomás de Aquino, 1965: 1 q.1 a.9). La poesía es ciencia ínfima. El Aquinate se adhiere en este tema a lo académico: Platón reconocía que "es ya antigua la disputa entre filosofía y poesía", y postulaba que "no han de admitirse en la ciudad más que los himnos a los dioses y los encomios a los héroes", porque de admitirse "la musa placentera en cantos o en poemas, reinarán en tu ciudad el placer y el dolor en vez de la ley y de aquel razonamiento que en cada caso parezca mejor a la comunidad" (Platón, 2011: 607a-b).

2 Estas expresiones se sitúan en el marco de una reducción de su carácter artístico a un ámbito extrínseco a la filosofía y a la teología. Probablemente esa reducción sea así porque domina el conocimiento de la Metafísica aristotélica y sabe que el esfuerzo de los primeros poetas teólogos, representaba un modo infantil de conocimiento racional del mundo (Eco, 1999: 94).

${ }^{3}$ Dante es todavía un artista medieval pues otorga mucha importancia al contenido, por lo que la gravitas sententiae sigue siendo vital para él, como comprobamos cuando afirma que "solamente los temas más excelentes son dignos de ser tratados en vulgar ilustre" (De vulg. Eloq. II, 2). Sus estructuras complejas le aproximan más al gótico que al humanismo renacentista. No es propiamente un humanista porque no concede a la inspiración y a la intuición poéticas la relevancia que da a la concepción racional del arte (recta ratio factibilium) que convierte en un diccionario de reglas, no en vano, para él los mejores poetas son los regulati, mientras declara que poetas insensatos son aquellos que fundan su originalidad en su exclusivo ingenio. 
Gran utilidad aportan universalmente las letras a todos los que se deleitan con ellas, pero mucho mayor la aportan sin comparación alguna a los escultores, pintores y arquitectos, pues embellecen y sutilizan las invenciones que nacen naturalmente en ellos. Es realmente la cosa más útil y necesaria para los ingenios milagrosos de estos artistas (Vasari, 2002: 314).

Fue a lo largo del siglo XIV cuando se llevó a cabo la defensa de la poesía, tenida como "formación humana", alcanzando la consideración de altera philosophia. Influyó notablemente Petrarca (1304-1374), quien desarrolló una concepción poética no sujeta a un código de reglas de coloribus rethoricis, de pericia técnica o preceptiva clásica. Al intelectualismo lógico escolástico le sucedió la capacidad poética nutrida no tanto de las reglas, esquemas pre-constituidos y complejidades góticas, como de la experiencia interior y personal que se sigue de la imitación, que no debe entenderse como fiel copia sino como invención. A partir de ahora, la belleza se corresponde con la fidelidad imitativa de lo real más el proceso de corrección interpretativa: imitando y sin embargo corrigiendo, tal es la doble exigencia (Panofsky, 2013: 62). Por primera vez, aflora una matización expresa a una explicación metafísica de lo bello, desuniéndose la cadena que en la Edad Media existía entre el bonum y el pulchrum. El trabajo del artista transita de la idea metafísica e intelectual de la Belleza a una idea de lo bello que se obtiene a posteriori de la observación y la corrección. Las observaciones y las correcciones son las operaciones que hacen visible lo que antes era un mero dato intelectual o trascendental apriorístico. En el Renacimiento, la metafísica ya no tiene la primera, sino la última palabra.

La actividad poética es creativa, más aún, es inventiva porque inventar es hacer visible, sacar a la luz, desvelar. Que el término humanitas guarde una relación de semejanza semántica con el término litterarum expresa la idea de que es a través de las letras como el hombre puede hacer visible lo humano ¿Qué es la humanidad? La perfección que es posible mediante las letras. Por eso, al estudio de las letras se les llama studia humanitatis: humanidades. Son las letras la forma con que el hombre deja ver la humanidad, como la perspectiva deja ver el espacio y la retórica deja ver el sentido de lo dicho.

En el humanismo renacentista, la cultura y el arte son las que hacen visibles expresándolas, la naturaleza, la verdad y la belleza. Ni la cultura, ni el arte, ni la poesía debieran entenderse como adornos o embellecimientos extrínsecos sino como medios esenciales para hacer visible lo oculto (Grassi, 1993: 82). Al res- 
pecto, tiene sentido la célebre carta que a la muerte de Petrarca escribe el canciller de Florencia Coluccio Salutati (1330-1406) donde sostiene que la armonía de la retórica puede educar a los hombres en una elevada humanitas. Y en otra carta dirigida al monje Giovanni de Samminia le replica que nada se parece más a la palabra de Dios que la poesía (Gilson, 1958: 442). Vasari insiste en la importancia de las letras cuando declara, a propósito de Alberti que:

(...) los escritos y consejos de los artistas doctos tienen por sí mismos mucha mayor eficacia y adquieren mayor crédito que las palabras o las obras de los que no conocen más que la mera práctica, ya la ejerciten bien o mal (...) Y que esto es cierto se puede apreciar claramente en el florentino Alberti (Vasari, 2002: 314).

\section{Vitruvio interpretado por Alberti.}

Desde muchos frentes, se afirma que León Battista Alberti (1404-1472), hijo de patricio florentino y considerado el primer teórico del clasicismo, escribe como un poeta (renacentista y humanista) ${ }^{4}$ un tratado de arquitectura, fundado en la retórica (ciceroniana). Anota Vasari que Alberti era más habilidoso con la pluma que con el pincel; más aún, que:

(...) no ha habido entre los artistas modernos ninguno que le haya podido superar en la escritura (...) Por eso no debe sorprender que Leon Battista Alberti sea más conocido por su escritura que por sus obras manuales (Vasari, 2002: 315).

En efecto, había tratados, pero no dejaban de ser más que recetarios enciclopédicos si no, biografías: la Schedula diversarum artium de Teófilo, el Trattato della pictura de Cennini, el De origine civitatis Florentiae de Filipo Villani, los Comentarii de Ghiberti y los Diez Libros de Arquitectura de Marco Vitruvio Polion, arquitecto romano del siglo I a.C., contemporáneo de Julio César y de Octavio Augusto a quien está dedicado este primer escrito, insólito en la antigüedad, sobre la arquitectura. De éste último, parece que Alberti manejo los manuscritos y no el incunable de 1486 que pudo salir del códice encontrado en Montecassino en 1414 (Chueca, 1989: 45).

De la biografía de Alberti deducimos que se hallaba más próximo a escritores humanistas que a los artesanos instruidos en los talleres de orfebrería o a los arquitectos constructores, no en vano es difícil encontrarlo dirigiendo y ejecu-

\footnotetext{
4 "Maquiavelo dijo de su casa que más parecía la de un príncipe que la de una familia privada" (Chueca, 1989: 38).
} 
tando las obras que había diseñado: a partir de 1450 la reconstrucción de San Francisco de Rimini, Santa María Novella, el palacio Rucellai, la capilla del Santo Sepulcro, y desde 1460 a 1472 las Iglesias de San Sebastiano y Sant Andrea.

El factor decisivo de toda la actividad artística de Alberti fue que su enfoque de la Antigüedad y la Rinascità, al que tal conmovedora expresión dio en sus tratados, fue fundamentalmente de origen literario (Heydenreich, 1991: 530-531).

Se situaba más cercano a la idea de genio que a la de gremio, y se identificaba más con la idea de estilo que con la de pericia. Fue un autor muy poliédrico, escribió comedias y obras filosóficas, llevó a cabo escritos de religión, ética, ciencias, también sobre la cría y monta del caballo, etc. Nos interesa ahora advertir que durante el decenio de 1430 aprendió el arte de la comunicación, por lo que la retórica y su técnica, ciertamente de índole ciceronianas, adquirieron en su formación y escritos una importancia inusual respecto de los tratados de arquitectura y arte que le precedieron. “Tres eran las cosas, según decía, en que no quería merecer el reproche de los hombres: en al andar, en el cabalgar y en el hablar" (Burkhardt, 1941: 92-93, en Chueca, 1989: 45).

Es sabido que la primera interpretación reflexiva y filológica del tratado de Vitruvio es obra de Alberti y en ella hallamos el primer tratado arquitectónico de la Modernidad. Debe apreciarse que en su obra De re Aedificatoria, como en la gran mayoría de los textos de los humanistas, la interpretación da lugar a la creación, esto es, a la invención. Virgilio leyó interpretativamente a Homero y alumbró la Eneida; Dante hizo lo mismo con la Eneida y generó la Divina Comedia ¿Qué es el Ulises de Joyce sino la experiencia crítica de la Odisea? ¿Qué es Anna Karénina sino una revisión de Madame Bovary de Flaubert? ¿No hallamos la crítica más elaborada del Otello de Shakespeare en el libreto de Boito para la ópera de Verdi? Una interpretación es una comprensión que se vuelve creación (Steiner, 1991: 24-27). No es ilógico que Alberti llevara a cabo su obra literaria desde la interpretación reflexiva del tratado vitruviano del que se sirvió para elaborar un texto que vinculó la arquitectura con la retórica elevándola sobre el mundo de las artes serviles y mecánicas, situándola en el de las liberales. Que la venustas vitruviana sea reemplazada por la gratiam, es sintomático de hasta qué punto el texto de Alberti explora la arquitectura desde una dimensión retórica. Superó la mera imitatio de la naturaleza y la rigurosa aplicación de normas y reglas propias de la Escolástica medieval, a 
través de la inventio que como es sabido es la primera actividad que debe llevar a cabo el buen orador en la preparación y pronunciación de un discurso ${ }^{5}$. Nótese que en el prólogo a la versión en vulgar del tratado Della pittura, Alberti concibe al arquitecto no sólo como artifex también como inventor ${ }^{6}$.

La diferencia más reveladora entre el tratado de Vitruvio y el de Alberti consiste en que aquel lleva a cabo una enciclopedia arquitectónica de óptica helénica, de aplicación en el ámbito de las artes serviles, mientras éste, realiza una obra poética de aplicación en el de las liberales. Utilizando la expresión del trívium medieval, el tratado romano haría referencia a la lógica y la gramática de la arquitectura, mientras el albertino haría referencia a la retórica. Y no en vano, advierte Panofsky:

Alberti aplica al oficio de pintor las categorías de la retórica clásica: invención, disposición (convertida en circonscriptione y compositione, y reemplazada unos cien años después por disegno), y elocución (convertida en receptione de lume y reemplazada unos cien años después por colorito). Y lo que es más importante, introduce -o mejor dicho, reintroduce- en la teoría de las artes figurativas lo que llegaría a constituirse en concepto central de la estética renacentista, el viejo principio de convenienza o concinnitas, cuya traducción más aproximada quizá sea el término "armonía": (El pintor) debe procurar, ante todo, que todas las partes concuerden entre sí; y lo harán si, en cuanto a cantidad, función, clase, color y en todos los demás aspectos, armonizan (corresponderanno) en una única belleza (Panofsky, 1991: 63).

Esta distinción se ve aumentada si se tiene en cuenta que Vitruvio escribe para un político como Augusto, mientras Alberti lo hace para un intelectual (un hombre de letras) como Poliziano, secretario privado de Lorenzo de Médicis (Masiero, 2003: 104), aunque realmente al primero al que se lo enseña es al Papa Nicolás V en 1452. Vitruvio inicia su tratado desde la teoría. Alberti, llega a ella. Vitruvio es un aristócrata. Alberti es un litterari, un hombre de

\footnotetext{
${ }^{5}$ Los primeros tratados de retórica latinos fueron la Retórica ad Herennium, de autor desconocido, y la obra ciceroniana De inventione. Allí se indican los oratoris officia que deben aplicarse en la composición, preparación y pronunciación de discursos: 1. La inventio, búsqueda de argumentos a favor o en contra; 2. La dispositio, ordenación de los materiales; 3 . La elocutio, forma verbal del contenido; 4 . La memoria, el recuerdo de los elementos en el momento preciso; 5. La actio, la forma externa, acción, entonación y gestos. ${ }^{6}$ En ese prólogo dedica el calificativo, inventor, a Brunelleschi.
} 
letras, un poeta. Vitruvio escribe desde un humanismo aristocrático; Alberti, desde uno humanismo pericial. Para Vitruvio, el origen de la arquitectura es de índole antropológica, "alrededor del fuego":

En la Antigüedad los hombres nacían en selvas, cavernas y bosques, como las fieras, y consumían su vida alimentándose de pastos silvestres. Pero en algún lugar, los árboles, agitados por la tempestad y por los espesos remolinos de viento y sacudidas entre ellas sus ramas, se incendiaron. $Y$ los que estaban cerca de ese lugar, espantados por la vehemencia de las llamas, huyeron. Luego, recuperada la calma, como advirtieron al acercarse de nuevo lo agradable para los cuerpos del calor del fuego, añadiéndole otros leños y conservándolo, convocaban a otros y les declaraban por señas sus utilidades (Vitruvio, (V. II/I. 1, 2 y 3.I: 63): 70-71).

Así, cuando hubo nacido un principio de encuentro y reunión y convivencia entre los hombres con ocasión de la invención del fuego, y se hallaron muchos en un mismo lugar poseedores por naturaleza del don, a diferencia de los animales, de andar erectos y no cuadrúpedos y contemplar así la magnificencia del mundo y de los astros, y fabricar además con facilidad cuanto quisieran con sus manos y sus articulaciones: en aquella concurrencia empezaron algunos a construir techos de ramaje; otros a vaciar cavernas debajo de los montes; otros en fin, imitando los nidos de las golondrinas y sus construcciones, a hacer de lodo y mimbres lugares en los que guarecerse. (Vitruvio, II/I. 6, 7 y 8.I: 64): 72).

En cambio, para Alberti, el origen de la arquitectura se basa en condiciones de habitabilidad:

En un principio -así lo creemos- el género humano se buscó lugares para descansar en cualquier sitio que fuera seguro y allí, una vez encontrada una zona apropiada y agradable, se estableció y tomó posesión del emplazamiento mismo, de modo y forma que no fue su deseo que se hicieran en el mismo lugar lo familiar y lo individual, sino que quiso que un lugar fuera para dormir, que en otro distinto se conservara el hogar, que cada cosa se emplazara en un lugar distinto según su función (Alberti, 1988).

\section{El trivium invertido: el primado de la retórica.}

Es ilustrativo, como anota Higinio Marín, que a diferencia del mundo y la ciencia griega, para los humanistas el decir sea revelador y transformador al mismo tiempo; signo que produce lo que significa: magia, técnica, arte, poder, poesía, estilo (Marín, 1997: 173-179). Un griego no pensaría un Dios que creara 
al decir. En cambio, los humanistas piensan sobre todo en uno creador, más incluso que redentor. No se quiere escuchar la naturaleza sino decirla y cumplirla, adornarla. No es el logos griego sino el verbum, la palabra que da lugar al discurso, la que permite desvelar y hacer visible lo real. La vita contemplativa más que ser rechazada es insertada en la vita activa donde ambas se conjugan con la forma de la creación, de la inventio (Marín, 1997: 179).

En el Renacimiento, el primado del saber recae del lado del ingenium y no de la ratio. Ahora es la libertad la que genera la lógica de la invención. El ingenium siempre da lugar a formas nuevas y eso es lo que ahora se llama creatividad. El trívium medieval deja de estar sujeto a la lógica de lo necesario y pasa a depender de la lógica de la libertad, de las acciones y sujetos singulares.

Como es sabido, el orden universitario del saber medieval quedaba recogido en el trívium (tres caminos) cuya estructura era: lógica, gramática y retórica. Dicho orden es revelador de una jerarquía respecto del saber, atribuyéndosele a la lógica y a la gramática un cierto primado directivo desde el que se gobernaría o deduciría la retórica. Este orden disciplinar del saber parece invertirse en el Renacimiento. No son la retórica y la gramática disciplinas subordinadas de la lógica, sino que más bien se han vuelto directivas respecto de la lógica y del saber mismo. La lógica mengua su carácter prescriptivo y pasa a ser aquello que se descubre, o mejor se descifra haciéndose visible, a través de la acción inventiva: el ingenium. Lo que la creatividad muestra es la lógica de la acción.

Ser poeta equivaldría en el Renacimiento a ser artifex e inventor: conocer las reglas no para aplicarlas mecánicamente, como si de un método se tratara dentro del ámbito gremial de las artes serviles, sino para mostrarlas y revelarlas a través del discurso poético. Los poetas utilizan el verbum para desvelar el logos. En poesía, la lógica no tiene la primera palabra sino la última. En el Renacimiento, la gramática no es lo que se sigue de las normas:

Para los humanistas, no es una grammatica especulativa artificiosamente deducida de unas reglas, sino lo hallado por el uso real de los espléndidos escritores, es decir el uso de la colectividad afinado por los hallazgos personales. No la teoría, pues, sino la historia (Rico, 1993: 43).

Frente al carácter inmutable y fijo de la lógica, de las normas y las leyes, los artistas renacentistas muestran que lo inalterable y estable recae del lado de las acciones libres de los hombres, de sus innovaciones y hallazgos. No es a través 
de la contemplación sino de la acción como las normas y las leyes se desvelan. Porque se buscan, se hallan, y por eso las muestran como si de una invención se tratara. Es la acción libre e histórica la que descubre que la norma puede renovarse sin desaparecer, y allí es donde parece reinar la retórica. Sin la retórica, la inmutabilidad y perennidad de lo real y lo natural no podrían descifrarse. No se trata de rechazar la contemplación sino más bien de insertarla en la vita activa donde ambas se conjugan bajo la forma de la creación.

Alberti es poeta porque inventa y descubre dibujando, tal es su modernidad. Eso no quiere decir que rechazara los cánones y las normas (la lógica y la gramática) más bien, muestra que tales reglas, subsistiendo, deben ser alumbradas, para lo que se requiere dibujar y proyectar. Las líneas son el lenguaje de la arquitectura. Esa es la importancia que le otorga al dibujo, los lineamenta, al que dedica el Libro Primero: "Será pues lineamento un trazado seguro y constante concebido en el ánimo, hecho de líneas y ángulos y acabado con ánimo e ingenio cultivado" (Alberti, 1988: 21). Y en el capítulo primero del Libro Primero anota:

Y toda la fuerza y la razón de los lineamentos radica en cómo ellos abren un camino recto y absoluto para acoplar y conjugar líneas y ángulos por medio de los cuales se comprende y se determina el aspecto del edificio (Alberti, 1988: 19).

El caso de Alberti no es el de un erudito que acumula conocimientos, preceptos y normas que receta para la construcción arquitectónica. Es un hombre de acción, un poeta, que junto a otros artistas del Renacimiento inauguraron la época del discurso, de la retórica y del buen uso como herramientas directivas del arte. La lógica y la gramática vitruvianas son tenidas por enciclopédicas, acríticas, manualísticas, acumulativas; las albertianas son poéticas, críticas, correctivas, inventivas.

La novedad más sustancial del tratado albertiano es el dibujo, los lineamen$t t a$, porque dibujar es construir; dibujar es para el arquitecto lo que escribir para el poeta; "ambos llevan a cabo sus obras". Su tratado puede entenderse como un discurso poético que utiliza el dibujo como instrumento básico por el que el arquitecto "probando y aprobando", desvela, e inventa una arquitectura que no incumple las leyes sino, más bien, las descifra haciéndolas visibles. El dibujo es a la arquitectura lo que la retórica es al conocimiento. 


\section{Concinnitas: Cicerón en arquitectura.}

La formación intelectual de Alberti parece tener muy presente la retórica. No en vano, asiste en Padua a la escuela de un ciceroniano y, en el decenio de 1430 se instruye en el arte de la comunicación. En 1444, residiendo en Roma, comenzó su De re Aedificatoria, obra que parece ser concebida en el pontificado de Eugenio IV y cuya primera versión, como hemos visto, fue mostrada al papa Nicolás V del que Alberti era asesor y consejero en relación a los magnos proyectos ideados por éste para la restauración de Roma. De Marco Tulio Cicerón (106-43 a.C.) toma prestado para su tratado arquitectónico, el término concinnitas y transpone al plano de las artes visuales la categoría retórica de la inventio, que aplicada al plano verbal puede entenderse como el hallazgo y encuentro de ideas.

La inventio está relacionada con la dispositio y ésta, según Laugsberg, puede entenderse como: "Disponer las ideas y pensamientos que hemos encontrado gracias a la inventio en orden tendente a la utilitas" (Laugsberg, 1990: 367-368) para luego pasar a la elocutio que "traslada al lenguaje las ideas halladas en la inventio y ordenadas por la dispositio" (Laugsberg, 1984: 9).

Cicerón consideraba la concinnitas como la cualidad suprema del discurso. Un buen discurso es aquel en el que no se da una sola palabra de más, ni de menos y todas y cada una de las palabras se hallan en su lugar justo. Alberti en el libro IV de su tratado sentencia que: "Juzgamos óptima aquella cosa que de suyo está hecha de tal modo que no se puede cambiarla si no es empeorándola" (Alberti, 1988: 277). La noción de belleza en Alberti está remitida a la concinnitas, porque la belleza es una concinidad (compostura, traduce Lozano) de todas las partes con relación a aquello a lo que pertenecen y porque la concinnitas es una cualidad del objeto que desmerece cuando algo se le añade, se le quita o se le cambia. El objeto justo es el probabilius, el más aprobado de todos, de suerte que de las variaciones, probatius, de tal objeto, sólo en una se cumple la concinnitas. Así lo advierte Alberti (1988: 447):

Ut sit pulchritudo

quidem certa cum ratione concinnitas

universarum partium in eo, cuius sint

ita ut addi

aut dimini

aut immutan possit nihil,

quin improbabilius reddatur. 
Probar y aprobar. Esa parece ser la norma que deben seguir el pintor, el escultor y el arquitecto para dar por concluida su obra. La belleza ya no es un mero dato, de índole trascendental, sino más bien el decantado de un proceso de disposición de elementos y partes hasta que no se desee más de lo que hay, ni se desapruebe parte alguna ¿Cómo averiguar que se ha alcanzado el punto en que nada falta y nada sobra? Alberti responde que cuando somos conmovidos y al punto sentimos lo que es cocino y la razón, en definitiva: cuando nos gusta.

El tratado de Alberti está relacionado con lo que Kant desarrolla en la Crítica del Juicio a propósito del juicio del gusto y que Wittgenstein abordará en Remarks on the Philosophy of Psychology como el proceso de búsqueda de la palabra correcta en su lugar adecuado. Por su apelación al gusto, se afirma que Alberti busca un consensus, un consenso común, situando la Arquitectura en la sensibilidad de todos.

La teoría de Alberti es una teoría estética poética porque fundada en el gusto va más allá de la mera ratio, la mera lógica y la gramática. La belleza ya no es la adecuación a un ejemplar teórico o trascendental sino algo hecho en la medida en que mediante la acción aparece una racionalidad antes oculta. Esta ratio no es tanto una condición, como aquello que se ha hecho visible y por eso agrada a todos. Y por ello, porque todos los hombres poseen un innato sentido de la belleza que le permite desear instintivamente esa armonía, mediada por el desinterés y no por la necesidad o la comodidad, el sentido de lo bello es común a todos: "Verum animis innata quaedeam ratio efficiet" (Alberti, 1988: 813).

Por eso a la concinnitas pueden acceder todos los hombres, porque anida en el ánimo una innata ratio que guía el juicio de lo bello de lo que produce placer. En el tratado de Alberti, el gusto debe moderar la obra. Pero aquí el gusto es el que se tiene a partir de los ojos y así nos lo indica en el Libro Segundo: "En este género de cosas, el sentido de los ojos es el más agudo de todos" (Alberti, 1988: 95).

La estética albertiana es una estética visual que precisa el dibujo, el trazado, los lineamentta, no en vano, la teoría de la arquitectura que Alberti propone se basa en la fórmula: Ver, linear, medir. 


\section{Los lineamentta como principio retórico: de lo servil a lo liberal.}

Alberti, uomo letterato, hijo de patricio, consejero y amigo personal de tres papas, debía conocer la distinción aristotélica entre artes serviles y artes liberales (Aristóteles, 2011: 2). Debía conocer el sistema de las artes que Galeno introdujo en la Edad Media en su Perì téchnes; debía dominar el sistema de las artes elaborado por Hugo de San Victor, Rodolfo de Longchamp y Domingo Gundisalvo, y que éste último, anota Umberto Eco, expuso su sistema en 1150, refiriéndose al Estagirita, en estos términos: "entre las artes superiores, bajo la entrada elocuencia, encontramos poética, gramática y retórica; las artes mecánicas están en el rango más ínfimo” (Eco, 1999: 133). Y continúa Eco destacando el carácter degradante del término "artes mecánicas o serviles", comprometidas éstas con la materia y la fatiga del trabajo manual y del hacer fabril: "Sucede a veces incluso que para dar una etimología del término mechanicae se piense en el verbo moechari (cometer adulterio), como, por ejemplo, Hugo de San Victor (Didascalicon II, 21, PL 176, col. 760 cfr. Schlosser 1924, pág. 78)" (Eco, 1999: 133).

Alberti conocía sobradamente que ni la pintura, ni la escultura, ni la arquitectura formaban parte de las artes liberales; carecían de musas porque las musas lo son de la palabra, el relato y los diferentes tipos de poesía (Otto, 2005). Conocedor de Vitruvio, sabría que, para éste, la única diferencia que había entre la arquitectura y la fabricación de sandalias era las grandes dificultades que representaba la primera (Vitruvio, 1987: 7). Debía saber que Cicerón llamó sórdido al arte de los arquitectos y dejó sin responder la cuestión de si el arte del pintor y del escultor debería o no incluirse en la misma categoría. Debía conocer que Séneca calificaba a los artistas visuales como esos luxuriae ministros, oponiéndose a incluirlos dentro de las artes visuales. Y no obstante, Alberti, con sus tratados sobre las artes visuales ${ }^{7}$-De pictura (14351436), De re aedificatoria (1444-1452) y De statua (1434-1435)- hizo que comenzaran el ascenso desde las artes serviles y mecánicas a las liberales.

En contraste con el universo cultural medieval, en el Renacimiento, ni la creación, ni la interpretación, ni la invención que comparecen en las artes vi-

\footnotetext{
7 A los tratados De pictura, De re aedificatoria y De statua conviene añadir Descriptio urbis Romae (1432-1434), Elementa picturae (c. 1435) y Della prospettiva (perdido) (Heydenreich, 1991: 530).
} 
suales obedecen a trabajos meramente mecánicos o fabriles, por lo que éstas comienzan a emanciparse de las artes serviles y van elevándose hacia la cumbre de las liberales (Tatarkiewicz, 2004: 144-145).

Es sintomático que sea difícil encontrar a Alberti dirigiendo las obras que diseñó a diferencia de Brunelleschi o Michelozzo que realizaron indicaciones concretas y específicas a sus colaboradores, artesanos y operarios a pie de obra. De sus trabajos podríamos referirnos del siguiente modo: "construcción, según diseño o idea de Alberti". El trabajo de arquitecto, en sentido estricto, como director de las obras que diseñó e ideo, recayó con frecuencia en manos de otros. En relación a la Iglesia de San Francesco en Rímini, comenzada en 1450 sabemos que:

Por encima de todo, Alberti luchó con los arquitectos para que respetasen las proporciones del proyecto, las cuales defendió con inquebrantable firmeza tanto en el casco de la cúpula como en el de la armadura de cubierta y fachada. (Heydenreich, 1991: 531-532).

Y es sabido que la fachada de Santa María Novella fue construida por el "arquitecto" Giovanni di Bertino, que el palacio Rucellai (1446-1451) fue materializado por Bernardo Rosselino y que en la Iglesia Sant'Andrea de Mantua, comenzada en 1452, Luca Fancelli fue el arquitecto encargado de la construcción que "siguió los planos del ya difunto Alberti al pie de la letra".

Alberti no fue un director de obra, ni un constructor que ejecutara sus proyectos al estilo de los arquitectos y maestros de obras góticos (Hughes Libergier, Pierre Montereau y Guillermo de Sens, entre otros) (Panofsky, 2007). Fue un intelectual, un poeta, un erudito humanista, un uomo letterato, que utilizó el dibujo para representar una arquitectura que ya en el dibujo era arquitectura. A partir de él cobra sentido la expresión docente "dibujar es construir". El dibujo, el trazado, el proyecto, en fin, los lineamentta, constituyen el modus operandi con que la labor del arquitecto humanista se sitúa en el ámbito de las artes liberales y no en el de las serviles, como sería el caso de los arqui-

${ }^{8}$ La ejecución del edificio estuvo en manos de Matteo de Pasti, Matteo Nuti, Alvise Carpentiere y otros, sin olvidar a Agostino di Duccio. Los documentos muestran muy claramente la colaboración entre estos capomaestri locales y el respeto que le tenían a Alberti, quien estuvo ausente, así como el interés que se tomó siempre el patrón. (Heydenreich, 1991: 531-532). 
tectos ejecutantes de sus disegnos e ideas. La importancia que otorga al dibujo de arquitectura parece ser, en esta disciplina, el impulso necesario que le permite elevarse sobre las artes mecánicas y serviles situándola en el ámbito de las liberales.

No obstante, insistamos, los lineamentta deben entenderse de manera mucho más amplia. No son meros dibujos, bocetos o esbozos que expresan una idea arquitectónica barruntada. Si Alberti pretende elevar la arquitectura al orden de las artes liberales, el dibujo debe entenderse como lo es la escritura para el poeta y la palabra para el orador ¿Qué son los lineamentta? un acto manual que no sigue a la inteligencia que concibe, sino que es inteligencia que concibe haciendo, dibujando, pero ese tipo de actividad es en suma: una actividad retórica. Bien podría considerarse lineamentta no sólo el trazado o proyecto, donde se verifica, prueba y aprueba intelectual y visualmente el acierto en el cuidado del numerus, de la finitio y de la collocatio de los elementos proyectados en orden a la concinnitas ${ }^{9}$, también el modo y la condición con que la idea y el disegno vienen a la mente y se abren paso. Dibujar es escribir, y más: dibujar también es construir, no en vano los escritores también llevan a cabo su "obra" literaria. Las líneas son al arquitecto lo que las letras al poeta en cuanto que líneas y letras son concebidas en el ánimo: "Y toda la fuerza y la razón de los lineamentos radica en cómo ellos abren un camino recto y absoluto para acoplar y conjugar líneas y ángulos por medio de los cuales se comprende y se determina el aspecto del edificio" (Alberti, 1988: 19).

El dibujo, desde Alberti, no es un mero trazado sino el campo de pruebas, donde se "prueba y aprueba", se añade y se quita, el número, disposiciones, repeticiones y proporciones. Sin los lineamentta, ¿cómo saber visualmente si el disegno obedece a criterios de gusto o de falta de él? ¿Cómo averiguar si le falta o le sobra algo? Probar y aprobar, ver, linear y medir, son la labor del erudito, del arquitecto humanista, que debe corregir y modificar, añadir y

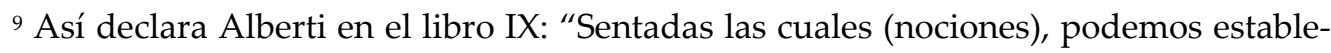
cer que la belleza es como un consentimiento y una coherencia de las partes en el todo al cual pertenecen, habidos por un número, una finición y una colocación acertadas, tal como la concinnitas, esto es la norma absoluta y primaria de la naturaleza, reclama" (Alberti, 1988: 817).
} 
quitar elementos y tamaños, proporciones y números hasta que nada sobre ni falte:

Muchas veces y mucho se ha de tratar en el ánimo y entendimiento, y en una cosa llana, o tablilla, o en otra cualquier cosa con modelos se ha de figurar antes toda la obra y cada una de sus partes sin pena añadiendo, o quitando qué, cual y cuán grande haya de ser el edificio. Porque hecha la cosa no te pese haberla hecho, y hayas de decir: esto no quisiera, más quisiera aquello (Alberti, 1988: 33).

Ciertamente en el proyecto o disegno hay una teoría que subyace, pero es según se ha indicado, a través de los lineamentta como se hace visible, porque proyectar arquitectura ya no es un acto manual, situado en las artes mecánicas, debe tenerse como inteligencia que concibe haciendo. De modo que el dibujo se convierte en la retórica del arquitecto porque es a través de él como se desvela la lógica y la gramática de la arquitectura, y cuando eso sucede entonces comparece la concinnitas. La teoría subyace, en efecto, pero sólo se hace visible dibujando. Insistamos: no es el dibujo un acto servil y manual que se sirve de un acto previo intelectual, liberal, que lo representa sino más bien el modo en que el acto mental concibe, a saber: dibujando. Así lo expresa Arnau: (...) "no es un a priori dado de una vez por todas, sino el decantado sucesivo de un proceso de prueba" (Arnau, 1988: 122).

\section{Lineamentta y buen gusto: saber mirar y saber "a-probar"}

La importancia dada a los lineamentta, guarda relación con el primado de lo visual que caracteriza el Renacimiento, sobre lo oral que caracterizaba la Edad Media, donde lo sagrado en su desvelamiento parecía estar más vinculado con el sentido del oído porque "a Dios no se le puede ver pero sí oír", diría Weber. En ello influye poderosamente el descubrimiento de la perspectiva. La perspectiva lleva implícita "la contemplación del mundo desde un único punto de vista, desde un ojo único" anota Chueca Goitia, y otorga una radical prevalencia al sujeto sobre el objeto, a las magnitudes sobre los valores, a lo cuantitativo sobre lo cualitativo, colaborando en el gran desplazamiento de lo oral y lo transmitido ex audito hacia lo visual, clausurándose la Edad Media artística e inaugurando la Modernidad caracterizada por su cientificidad, dirá Panofsky. Leonardo da Vinci (1452-1519) advierte en el aforismo 326:"El ojo es el más digno de los sentidos por ser el que con mayor exac- 
titud capta los objetos, mientras que el oído es muy inferior por su mayor imprecisión" (Da Vinci, 1965: 34-37 y 314-450). En la misma línea anota Alberti: "En este género de cosas, el sentido de los ojos es el más agudo de todos". Desde Alberti, la arquitectura se experimenta como si se viera. La hegemonía del dibujo guarda relación con una arquitectura hecha para ser vista, por eso su esencia reside en la línea. Los lineamentta asumen in nuce la re aedificatoria.

Hemos traído a colación esta transmutación de lo oral en favor de lo visual como consecuencia de la importancia que Alberti otorga al dibujo, al veredicto del ojo y al gusto como elementos de verificación de la concinnitas:

Ante todo, los ojos son ávidos por naturaleza de hermosura y de concinnitas, y en este asunto se muestran meticulosos y sobre manera difíciles. Y no sé de donde procede que soliciten lo ausente más que alaban lo presente. (...) De modo que el ojo discurra suave y libremente como fluyendo a lo largo de cornisas, intervalos y toda apariencia interior y exterior de la obra, aumentando el placer con el placer de lo uno y de lo vario (Alberti, 1988: 851).

Y nos preguntamos cómo averiguar si lo que el ojo ve es hermoso o no ¿Cómo saber que lo que complace a la vista, es hermoso? ${ }^{10} \mathrm{Y}$ más: en virtud de qué criterio sabemos que a la cosa edificatoria le puede sobrar o faltar alguna medida, número o proporción. Creemos que ese criterio o instancia no es otra que "el gusto". Como es sabido, el gusto es uno de los cinco sentidos pero a poco que profundicemos, notamos que es el gusto quien designa la relación de congruencia y armonía entre la parte y el todo, entre lo particular y lo general, entre la norma y el modo en que ésta se aplica. Lo sabemos por Tomás de Aquino cuya obra debió conocer Alberti, no en vano estudió derecho canónico: de donde lo bello consiste en una debida proporción porque los sentidos se deleitan en las cosas que les son debidamente proporcionadas sicut sibi similibus (Tomás de Aquino, 1965: I q.5, a.4 ad 1). El gusto es la constatación de la adecuación del sujeto con el objeto, es el placer del reconocimiento de tal armonía, proporcionalidad y al cabo el placer de la concinnitas, cualidad suprema del discurso retórico que Alberti hereda de Cicerón: “Juzgamos óptima aquella cosa que de suyo está hecha de tal modo que no se puede cambiarla si no es empeorándola" (Alberti, 1988: 277) (...) "Que la hermosura es, en efecto, una determinada compostura de las partes con relación a

${ }^{10}$ Pulcrhum est id quod visum placet. "Es hermoso lo que complace a la vista". 
aquello a lo cual corresponden, de modo que nada se pueda añadir, o disminuir, o cambiar, sin que ello quede menos aprobado" (Alberti, 1988: 447).

Y al respecto, resulta revelador que más de cinco siglos después Wittgenstein (1889-1951) se planteara la misma cuestión, probando y aprobando:

¿Cómo encuentro la palabra correcta? ¿Cómo elijo entre las palabras? Verdaderamente es como si comparara entre sí las palabras según delicadas discriminaciones de gusto. Esta es demasiado... ésta demasiado... Esta es la correcta. Pero yo no necesito siempre juzgar, explicar, por qué ésta o esa no es la palabra correcta. Simplemente no es todavía la correcta. Continuo la búsqueda, no estoy satisfecho. Este es exactamente el aspecto con que aparece la búsqueda y este es exactamente el aspecto con que aparece el encontrar (Wittgenstein, 1980: 362).

Lo que parece derivarse del texto de Wittgenstein es que la búsqueda se funda en el criterio del gusto, porque es el gusto el sentido que detecta la adecuación y la armonía de las partes en relación al todo, y al cabo, de lo individual a lo general. Es el gusto el que nos indica qué sobra y qué falta y, no en vano, cuando queremos saber si una cosa "está en su punto" la probamos y luego la aprobamos o desaprobamos. Viene al caso recordar que el verbo sapere, de raíz latina, guarda relación etimológica con el sentido del gusto y del juicio, y poseer esa capacidad de aprobación o desaprobación convirtió al ser humano en sapiens. La sapiencia ha sido reconocida como la capacidad de conocer por el gusto, al menos en nuestra lengua lo sabemos bien, pues la palabra "saber" se puede aplicar tanto al sabor como al saber. Probar es degustar y para hallar la palabra correcta, el número, posición, tamaño y proporción adecuadas de algo ponemos y quitamos, añadimos, disminuimos y cambiamos.

El gusto no es propiamente el fundamento de lo bello sino más bien el sentido y dimensión necesarios que constatan la armonía y la disarmonía. Por gusto debiera entenderse en Alberti lo mismo que en la obra del Aquinate: el contacto entre la subjetividad y lo real donde surge, para la interioridad subjetiva, un saber inmediato sobre la congruencia entre las partes y el todo. Quizá por eso, porque el gusto aquí, en arquitectura, precisa del ojo y juzga la armonía y la proporción:

Las artes pertinentes e incluso necesarias al arquitecto son la pintura y la matemática. Que sea entendido en lo demás no me preocupa (...) Pero de la pintura y de la matemática no podrá prescindir más que el poeta de las sílabas y de la voz (Alberti, 1988: 861). 


\section{Conclusión.}

Alberti ofrece un tratado que no es sólo un conjunto de reglas, al estilo normativo del romano. Si un tratado contuviera las normas y las reglas, y al mismo tiempo el modo en que éstas han de aplicarse, sin dejar margen a la libertad, la Arquitectura sólo sería un arte mecánico sustanciado en la aplicación mecánica, servil y gremial, de preceptos legales y formales. Sin embargo, si, como entendemos, Alberti pretende elevar la Arquitectura al ámbito de las artes liberales debe introducir un criterio de legitimación interpretativa de la norma edificatoria que deje margen a la libertad. Ya se dijo que cuando la interpretación es reflexiva da lugar a la creación porque la arquitectura como la poesía y la pintura no es un tipo de saber teórico sino práctico. Y justamente porque la Modernidad se funda sobre la invención de la perspectiva, la prevalencia del punto de vista y el primado de lo visual sobre lo oral, el arquitecto utiliza el dibujo, los lineamentta como si estuviera pintando, para exponer lo pintado a la contemplación visual y a la reflexión, quedando así el proyecto sujeto a la aprobación o desaprobación del gusto: al sapere.

Quedar sujeto al gusto no conduce en el planteamiento de Alberti ni al irracionalismo ni al subjetivismo porque el gusto, lejos de ser una realidad privada, debiera entenderse como fenómeno social que no significa, caer en las redes de la moda o en el imperio de un fenómeno social. Más bien, guarda relación con eso que Gadamer define como el asentimiento de una comunidad ideal, es decir, el sentido común. De hecho, el propio Alberti se adelanta al riesgo de irracionalismo porque para el humanista, en clara simpatía con el pensamiento de Tomás de Aquino, hay cosas que nos gustan porque tendemos a ellas y si la tendencia al fin es natural, el gusto también lo es porque el hombre posee un innato sentido de la belleza y le apetece natural e instintivamente esa armonía:

Pero que cosa sea de suyo la hermosura y el ornato y en qué difieran, acaso lo intuyamos en nuestro ánimo con más claridad de lo que yo pueda expresarlo con palabras (Alberti, 1988: 447) (...) "Verum animis innata quaedan ratio efficiet" (Alberti, 1988: 813).

Anida en el ánimo una innata ratio que guía el juicio de lo bello por aquello que produce placer. Esta disposición es común a todos los hombres y se rige por la ratio, la relación belleza/placer: "Natura enim optima concupiscimus et 
optimis, cum voluptate adheremus" (Alberti, 1988: 815). Por naturaleza apetecemos lo mejor y nos adherimos a lo mejor con placer.

\section{Bibliografía}

AlBERTI, Leon Batista (1988): De re Aedificatoria, en ARNAU, Joaquín. La teoría de la arquitectura en los tratados: Alberti. Tebar Flores. Madrid.

ARISTÓTeles (2011): Poética; Magna Moralia. Gredos, Madrid.

ARISTÓTELES (2011): Política. Tecnos, Madrid.

CHUECA GoITIA, Fernando (1989): Historia de la arquitectura occidental, V Renacimiento. Dossat/Bolsillo. Madrid.

DA VINCI, Leonardo (1965): Aforismos. Espasa Calpe. Madrid.

ECO, Umberto (1999): Arte y belleza en la estética medieval. Lumen. Barcelona.

GILSON, Etienne (1958): La filosofía en la Edad Media, Tomo II. Gredos, Biblioteca Hispánica de Filosofía. Madrid.

GRASSI, Ernesto (1993): La filosofía del humanismo. Anthropos. Barcelona.

HEYDENREICH, Ludwig - LOTZ, Wolfgang (1991): Arquitectura en Italia 14001600. Cátedra. Madrid.

LAUGSBERG, Heinrich (1984): Manual de retórica literaria Tomo II. Gredos. Madrid.

LAUGSBERG, Heinrich (1990): Manual de retórica literaria Tomo I. Gredos. Madrid.

MARíN, Higinio (1997): La invención de lo humano. La construcción socio-histórica del individuo. Iberoamérica. Madrid.

MASIERO, Roberto (2003): Estética de la arquitectura. Machado Libros. Madrid.

OтTO, Walter Friedrich (2005): Las musas y el origen divino del canto y la palabra. Siruela. Madrid.

PANOFSKY, Erwin (1991): Renacimiento y renacimientos en el arte occidental. Alianza Universal. Madrid.

PANOFSKY, Erwin (2007): La arquitectura gótica y la escolástica. Siruela. Madrid.

PANOFSKY, Erwin (2013): Idea. Cuadernos de Arte Cátedra. Madrid.

PLATÓN (2011): República. Alianza Editorial, Madrid.

Rico, Francisco (1993): El sueño del humanismo. De Petrarca a Erasmo. Alianza Universidad. Madrid.

STEINER, George (1991): Presencias reales. Ensayos/Destino. Barcelona.

TATARKIEWICZ, Wladyslaw (2004): Historia de seis ideas. Arte, belleza, forma, creatividad, mímesis, experiencia estética. Tecnos. Madrid. 
TOMÁS DE AQUinO, Santo (1965): Summa Theologiae. Editorial Católica, Madrid.

VASARI, Giorgio (2002): Las vidas de los más excelentes arquitectos, pintores y escultores italianos desde Cimabue a nuestros tiempos. Cátedra. Madrid.

VITRUVIO (1987): De Architectura, en ARNAU, Joaquín, La teoría de la arquitectura en los tratados: Vitruvio. Tebar Flores. Madrid.

WiTtGensteIN, Ludwig (1980): Remarks on the Philosophy of Psychology. Blackwell. Oxford. 